\title{
Report on the Scottish Trainees' Day
}

A meeting for the trainees in psychiatry in Scotland was held at Murray Royal Hospital, Perth, on 2 October 1986. It was organised by the Scottish representatives on the Collegiate Trainees' Committee and was attended by 43 trainees of whom four were senior registrars. Its function was to bring trainees up to date on political issues which may affect them and to allow CTC representatives to hear the trainees' views so that they may reflect them more accurately. The first part was concerned with future manpower planning in psychiatry. Dr Robert Davidson, Physician Superintendent, Gartloch Hospital, Glasgow (Chairman of the Working Party which produced the Scottish Division's report on Manpower) and Dr Dallas Brodie, Senior Registrar in Psychiatry, Douglas Inch Centre, Glasgow (Chairman of the Scottish Hospital Junior Staffs Committee and a former member of the Collegiate Trainees' Committee) contributed.

\section{Manpower}

Dr Davidson established that few of the trainees present had read his Committee's Manpower Report, which had recently been published in the Bulletin. ${ }^{1}$ While other proposed solutions to manpower problems reflected a more radical approach to medical staffing, ${ }^{2}$ the Scottish Division's Report had a more pragmatic philosophy, suggesting changes within the existing manpower structure in Scottish psychiatry. One of the major difficulties in preparing the report was gathering accurate data from the Scottish Home and Health Department, even on such basic issues as how many doctors were working in a particular grade at a particular time. It is interesting to note that this difficulty was shared by the College Working Party reporting to JPAC (Joint Planning Advisory Committee) in England and Wales.

He outlined the proposals which had previously been published; these involved an expansion in consultant numbers, maintaining of consultant/SR ratio, central manpower control of the registrar grade in line with expected SR vacancies and an expansion of the SHO grade, particularly for those in training for general practice. A proposal that all psychiatric trainees should spend a period working in a peripheral hospital anticipated some of the discussion later in the day.

Dallas Brodie spoke on the document Hospital Medical Staffing-Achieving a Balance, otherwise known as the 'Hayhoe' Report. Again, it appeared that while some trainees had knowledge of the broad outline of these recommendations, few knew them in any detail. Dr Brodie reminded trainees that this document had its origins in a request from the Hospital Junior Staff's Committee to Victor Paige, the erstwhile Chairman of the NHS Management Board, to do something about what they saw as a worsening of promotion for junior hospital doctors. He summarised its major recommendations, and commented on the importance of its commitment to expansion in consultant numbers of $2 \%$ per annum. ${ }^{3}$

In discussion, concern was expressed at the new two-tier system for registrar training, with area registrars who would be expected to be senior registrars and district registrars who would be overseas doctors in this country for a limited period of post-graduate training. Dr Bodie did not believe that the district registrars would receive a poorer training as they would be part of the same training scheme as area registrars and would rotate through the same posts. The point was made that there had not been a tradition of large numbers of overseas doctors in registrar posts in Scotland and so some of the district registrars posts might remain vacant or be filled by UK graduates intending a career in psychiatry. However Dr Brodie's understanding was that these posts would not be available to UK graduates, and that if these posts were to remain vacant the Scottish Home and Health Department would be asked to upgrade them to consultant posts. It was noted that the report was produced for England and Wales and that adaptations would be necessary to take account of the different staffing situations in Scotland.

The other major area of concern was the new intermediate service grade (ISG) which was regarded as an unattractive proposition because of lack of promotion prospects and type of work which would be expected to be done. $\mathrm{Dr}$ Brodie felt it was unlikely that doctors in these posts would participate in heavy duty rotas because the nature of their contracts would make this expensive for Health Boards and would be an inefficient use of doctors in this grade. He stressed that the numbers would be relatively small, restricted to $10 \%$ of all consultant numbers, meaning at most 30 doctors working in such a grade in psychiatry in Scotland. Concern was expressed that doctors in ISG posts might permanently occupy desirable training posts such as liaison psychiatry or psychotherapy, thereby depriving rotational trainees of such experience. In summary, Dr Brodie said that the proposed arrangements in the Hayhoe Report were as good a deal as junior hospital doctors could expect at present and the proposals were broadly in line with those of the Scottish Division's Report on Manpower. It did seem that trainees were happier about the recommendations following the talk and discussion.

The role of central and peripheral hospitals in training

The broad theme of manpower continued in the next two talks from Drs David Tait, Murray Royal Hospital and Ian Pullen, Royal Edinburgh Hospital. If, as seems likely, the number of registrars training for a career in psychiatry is to be limited, the question remains of where these doctors should be trained. ${ }^{4}$ Drs Tait and Pullen debated the relative merits of 'peripheral' and 'central' hospitals in psychiatric training. The debate had a combative but good-humoured style; both speakers had trained as registrars at the Royal 
Edinburgh Hospital, the nearest thing Scottish psychiatry has to an ivory tower. Dr Tait was willing to acknowledge his Damascus-type conversion on coming to work in Perth.

Dr Tait said that the two most often quoted advantages of training in an 'ivory tower' were better didactic teaching and better research experience. He doubted the value of such didactic teaching and suggested it might be stifling professionally because it did not promote enquiring and critical thought. He said that, in Scotland at least, the best current research was being produced from 'peripheral' hospitals, namely Dumfries and Lochgilphead. He felt the advantages of training in peripheral hospitals were a greater sense of individual responsibility for patient management and a more static population. This allowed a better sense of the natural history of the illness and more established links with GPs. He stressed the value of the apprenticeship-type of training and experience in institutional management which can be gained working in a hospital with a smaller number of staff. Finally, he made the point of the importance to the hospital of having psychiatric trainees. A turnover of junior medical staff helped to stimulate the consultants, bringing in new ideas and prevented the hospital from becoming too inward looking.

Dr Pullen spoke of what he looked for in a registrar training scheme when starting in psychiatry and felt that this could be provided only in a large training hospital (Dr Tait had already said that the distinction between teaching and non-teaching hospitals was an English phenomenon). He felt that a large number of consultants allowed the experience of seeing many different ways of working; senior registrars kept one up to date with the latest developments, and a large registrar/sHo peer group allowed for greater mutual support and greater political clout. Hospitals with academic units had better post-graduate courses with more authoritative local speakers and attracted better quality outside speakers. He also stressed the access to good libraries and to research expertise. He felt that the priority at registrar level should be to obtain the best basic grounding in general psychiatry and the best chance of passing postgraduate examinations and these opportunities were to be found in academic teaching hospitals. Different ways of working could be experienced at senior registrar level and perhaps attachments to peripheral hospitals would be best arranged at this stage of the training.

In discussion it was suggested that perhaps specialist training opportunities can be less in central hospitals with large numbers of trainees because of the greater competition for particular training slots and Dr Pullen accepted this, saying that at present those that get the best experience of specialist training may be those trainees in the periphery who are seconded to specialist units in the central hospitals. Dr Tait accepted the principle that peripheral hospitals may not be able to provide the full range of specialist experience and that secondment is necessary.

A small group of trainees discussed the central/peripheral issue in greater depth; the case was made that all Scottish hospitals could be regarded as peripheral and this working group came down strongly in favour of experience in peripheral hospitals being mandatory at SHO/registrar level. Interestingly, this proposal was also made by Dr Davidson in his manpower report and by Dr Brodie in his talk; it would seem that this is perhaps an idea whose time has come. Peripheral experience as a senior registrar was seen as a less appealing option. At this career stage trainees are more likely to have domestic commitments which would make it difficult for them to move and ongoing research projects may also limit one geographically.

\section{Training for the new Membership}

In the afternoon Dr A. F. Cooper, Levendale Hospital, Glasgow (Specialty Adviser in Psychiatry in the West of Scotland) spoke of the implications of the new MRC Psychs examination for training in both the formal and informal sense. He gave details of the changes in the West of Scotland Post-Graduate Day-Release Course. In Part 1 there was to be a new 20-hour lecture course on descriptive psychopathology. The present psychology course should be moved to the second or third year and the amount of time allocated to psychodynamic psychotherapy would have to be reduced to allow for this. He also spoke on the implications for training at the base hospital. The examination would require more training in clinical methods and this could be done through direct supervision of trainees' interviewing techniques by consultants and the use of video. Dr Cooper said that it seemed likely that success in Part I of the MRC Psych would become a prerequisite for promotion to the registrar grade and, whilst there was some disquiet expressed that it may be advantageous to delay taking this examination into the second or third year of training, he felt that this factor would encourage trainees to take it early.

In discussion there were differing opinions on the most appropriate place for basic sciences to be tested. Some felt that they should be "got out of the way" in the First Part while others felt they should be integrated more with clinical practice and so examination in both Parts was appropriate. The extent to which interview technique can be trained was also raised. Some felt that this ability was intuitive and a bad interviewer could not be taught to be a good one.

\section{Working parties}

In the afternoon there were three working groups: on manpower, on peripheral training and on part-time training in psychiatry. The outcome of the two former groups was included earlier in this report. The latter group was a small but radical gathering who looked at the present position of part-time training in psychiatry in Scotland and made proposals for the future; it dealt mostly with the senior registrar training. As psychiatry attracts a high proportion of women doctors, the specialty must take the lead in planning and providing part-time training. It was accepted that numerically the provision of such training in Scotland is rather better than elsewhere, with about $12 \%$ of senior registrars working part-time. However, the geographical distribution was unequal and people interested in working part-time were usually not mobile and therefore could not move to where the jobs are. The suggestion was made that there 
should be a central Scottish pool of part-time senior registrar posts for which trainees would apply and if accepted would take up the posts in their local approved SR rotation scheme, with the Health Board being provided with funding to pay the salaries. As it is unlikely that new jobs will be created, this scheme would involve areas donating existing posts (perhaps one whole-time equivalent post each from Aberdeen and Dundee and two whole-time equivalent posts each from Glasgow and Edinburgh) to this central pool. The working group felt that with part-time posts being scarce it is unreasonable that one trainee should occupy such a post, particularly in the sub-specialties, for six years and that contracts in part-time posts should be held for a period of three years in the first instance. It was agreed to take these proposals to the Collegiate Trainees' Committee for further consideration.

The whole of Scotland is considered as a single division by the Royal College of Psychiatrists and because of its geography and the large numbers of trainees in Scotland, opportunities to meet as a group are rare. It was noted that those attending were predominantly SHOs and registrars and that relatively few trainees came from the larger centres of Edinburgh and Glasgow. The reason for this bias towards junior trainees from peripheral hospitals is difficult to explain. It may be that this group feels more vulnerable academically and politically and feels more need to keep up to date on these issues. It was certainly useful for the cTC representatives to hear the views of a group generally under- represented within the College and we hope that we will be able to reflect their views over the coming years. It is now CTC policy for representatives to meet with trainees at least twice a year. It could be difficult to have a full Scottish Meeting twice yearly and perhaps this requirement would be better fulfilled by arranging meetings within smaller areas such as already happens in Glasgow.

\section{Peter Rice \\ Lecturer, University \\ Department of Psychiatry Ninewells Hospital, Dundee \\ IAN MEDLEY \\ Registrar in Psychiatry Gartnavel Royal Hospital, Glasgow}

ReFERENCES

${ }^{1}$ Davidson, R. (Convenor) et al (1986) Scottish Division: Manpower Report. Bulletin of Royal College of Psychiatrists, 10, 196-198.

${ }^{2}$ WATSON, J. P. (1986) Calculating a District's psychiatric manpower. Bulletin of Royal College of Psychiatrists, 10, 334-337.

${ }^{3}$ DHSS Joint Consultants' Committee, Chairman of Regional Health Authorities (1986) Hospital medical staffingachieving a balance. British Medical Journal, 293, 147-151.

'MACKay, A. V. P. (1984) A Reply to the President's Letter. Bulletin of Royal College of Psychiatrists, 8, 62-64.

${ }^{5}$ Working Party For Review of MRC Psych (1986) A Report to the Court of Electors. Royal College of Psychiatrists.

\section{The College Library}

During the last six months the College has continued to receive many generous gifts. The Librarian wishes, in particular, to thank Dr I. C. Lodge Patch for donating a valuable collection of books as well as the following Members for copies of their own works:

Dr P. A. Barker Basic Family Therapy, 2nd edition

Dr T. C. M. Carnwath Behavioural Psychotherapy in Primary Care: $A$ Practice Manual

Dr J. Catalan Attempted Suicide, 2nd edition

Dr K. A. Day Behaviour Problems in Mental Handicap: Bibliography 1970-85

Professor H. Freeman Progress in Behaviour Therapy

Professor D. Goldberg Psychiatry in Medical Practice

Professor P. Graham Child Psychiatry: A Developmental Approach

Dr K. Hawton Attempted Suicide, 2nd edition

Dr J. Hughes Cancer and Emotion

Dr D. Kelly A Practical Handbook for the Treatment of Depression

Professor I. Kolvin Help Starts Here
Dr M. Lemlij Entre el Mito y la Historia: Psicoanalisis y Pasado Andino; Alucinogenos y Shamanismo en el Peru Contemporaneo

Dr M. I. Levi MCQs for the MRCPsych, Part I

Dr G. McGrath Common Psychiatric Emergencies

Professor P. McGuffin Scientific Principles of Psychopathology; A Psychiatric Catechism

Dr B. Mahendra Depression: The Disorder and its Associations

Professor I. M. Marks Fears, Phobias, and Rituals: Panic, Anxiety and their Disorders

Dr H. Maxwell An Outline of Psychotherapy

Dr M. R. Oates Understanding Child Abuse, 2nd edition

Dr R. Paul A Textbook of Clinical Neurophysiology

Dr D. J. Power Criminal Law and Psychiatry

Dr A. V. Rao Depressive Disease

Dr K. J. B. Rix A Handbook for Trainee Psychiatrists

Sir Martin Roth The Reality of Mental Illness

Dr D. A. Spencer Meanwood Park Hospital

Dr P. Tyrer Models for Mental Disorders

Professor D. J. West Sexual Crimes and Confrontations 